\title{
Healing-Promoting Action of the Zinc-Cimetidine Complex on Acetic Acid-Induced Gastric Ulcers in Rats
}

\author{
Mikio Ito, Kazuhide Inaguma, Yoshinori Suzuki, Tetsuya Segami and Yoshio Suzuki \\ Department of Pharmacology, Faculty of Pharmacy, Meijo University, 150 Yagotoyama, Tenpaku-ku, Nagoya 468, Japan \\ Received August 8, 1994 Accepted April 17, 1995
}

\begin{abstract}
We investigated the effect of the zinc-cimetidine complex on the healing of acetic acidinduced gastric ulcers in rats. When the effects of test drugs were assessed on the 15 th day after acetic acid injection, the zinc-cimetidine complex at oral doses of 15.0 (11.4 mg as cimetidine), 30.0 and $60.0 \mathrm{mg} / \mathrm{kg}$ twice daily promoted the ulcer healing in a dose-dependent manner. Cimetidine was effective at oral doses of over $45.4 \mathrm{mg} / \mathrm{kg}$ twice daily. $\mathrm{ZnCl}_{2}$ was ineffective on all ulcer parameters. The effect of the combination of cimetidine and $\mathrm{ZnCl}_{2}$ was similar to that of cimetidine alone. The zinc-cimetidine complex had already inhibited the increase in thiobarbituric acid reactants in the ulcerated region before the ulcer-healing effect of this compound was recognized. A single oral administration of the complex at 15 and $30 \mathrm{mg} / \mathrm{kg}$ to normal rats was ineffective in inhibiting acid secretion and in increasing serum gastrin levels, although cimetidine was markedly effective on both parameters. These results indicate that the zinc-cimetidine complex at about $1 / 4$ the dose of cimetidine was as effective as cimetidine when the ulcer-healing effects of both compounds were compared with the same dose of cimetidine. In addition, the ulcer-healing effect of this complex may be due, at least in part, to the inhibition of lipid peroxidation but not due to the inhibition of acid secretion or the trophic effect of gastrin.
\end{abstract}

Keywords: Zinc, Cimetidine, Gastric ulcer, Lipid peroxidation

The zinc-cimetidine complex has the chemical structure shown in Fig. 1. Cimetidine, one of the components, is a histamine $\mathrm{H}_{2}$-receptor antagonist that has a potent and long-lasting antisecretory action and has been widely used for the treatment of peptic ulcers. On the other hand, the effectiveness of zinc compounds in accelerating the healing of wounds is well established $(1,2)$. Furthermore, zinc has been shown to have a preventive effect on experimentally induced acute gastric lesions in rats $(3-5)$. It has been suggested that the preventive action of zinc on these gastric lesions may be associated with the inhibition of gastric mucosal mast cell degranulation $(6,7)$ and the stabilization of lysosomal membranes (8). From the above findings, the zinc-cimetidine complex is expected to possess a more beneficial effect than that of zinc or cimetidine alone on ulcer healing or the inhibition of ulcer formation by a synergistic action of both components.

The aim of the present study was to investigate the effect of the zinc-cimetidine complex in comparison to cimetidine or $\mathrm{ZnCl}_{2}$ on the healing of acetic acid-induced gastric ulcers in rats with a limited food intake time (9). Furthermore, to elucidate the mechanism of the ulcer healing-promoting action of the zinc-cimetidine complex, we investigated the effect of this compound on gastric acid secretion and serum gastrin levels. Recently we have demonstrated that oxygen radicals and lipid peroxydation may be involved in the healing of acetic acid-induced gastric ulcers in rats with a limited food intake time (10). In addition, we have demonstrated that the scavenging of

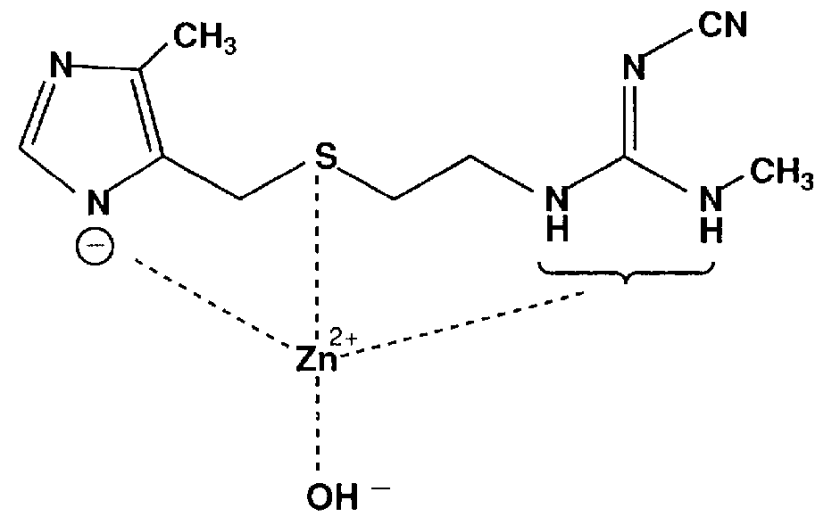

Fig. 1. Chemical structure of the zinc-cimetidine complex. 
oxygen radicals in the ulcerated region by free radical scavengers is effective in promoting ulcer healing. It has been shown that polaprezinc, a new antiulcer agent that is a chelate compound of L-carnosine and zinc, possesses a potent antioxidative action $(11-13)$ and is effective in healing chronic gastric ulcers in rats (14). From this finding, the zinc-cimetidine complex may also possess an antioxidative action. Therefore, we examined the effect of the zinc-cimetidine complex on thiobarbituric acid-reactive substances, an index of lipid peroxidation, in the ulcerated region.

\section{MATERIALS AND METHODS}

\section{Animals}

Male Sprague-Dawley strain SPF rats (Nippon SLC, Shizuoka), weighing 170-180 g, were used in the experiment. The animals were housed in an air-conditioned room at $23 \pm 1^{\circ} \mathrm{C}$.

\section{Drugs}

The drugs used were the zinc-cimetidine complex (The Foundation of Research Institute for Production Development, Kyoto), cimetidine (Sigma Chemical Co., St. Louis, MO, USA), $\mathrm{ZnCl}_{2}$ (Kanto Chemical Co., Inc., Tokyo) and human $\mathrm{Cu}, \mathrm{Zn}-\mathrm{SOD}$ (superoxide dismutase; Ube Industries, Ltd., Tokyo). The zinc-cimetidine com- plex and cimetidine were suspended in $1 \%$ gum arabic. $\mathrm{ZnCl}_{2}$ and human $\mathrm{Cu}, \mathrm{Zn}$-SOD were dissolved in $1 \%$ gum arabic and $0.9 \% \mathrm{NaCl}$.

Induction of gastric ulcers in rats with food intake time

The rats were allowed access to commercial food pellets freely only between 9:00-10:00 a.m. and 5:00-6:00 p.m. every day throughout the experimental period from 3 days prior to the ulcer induction. However, tap water was always supplied ad libitum. Gastric ulcers were induced in the rats whose feeding time was limited by injection of $20 \%$ acetic acid $(\mathrm{v} / \mathrm{v})$ in a volume of $0.05 \mathrm{ml}$ into the submucosal layer at the junction of the fundus and antrum in accordance with the method described by Takagi et al. (15).

\section{Ulcer-healing effects of test drugs}

The zinc-cimetidine complex, cimetizine, $\mathrm{ZnCl}_{2}$ or cimetidine $+\mathrm{ZnCl}_{2}$ was given orally, twice daily (10:30 a.m. and 6:30 p.m.) in a volume of $0.5 \mathrm{ml}$ per $100 \mathrm{~g}$ of body weight for 14 consecutive days from the day (the 1 st day) after acetic acid injection. Control animals were given only the vehicle ( $1 \%$ gum arabic) instead of test drugs. On the 15 th day, the animals were killed by rapid decapitation. The stomachs were removed, filled with 5 $\mathrm{ml}$ of $10 \%$ formalin and allowed to stand for $5 \mathrm{~min}$. Then, the stomachs were cut open along the greater curva-
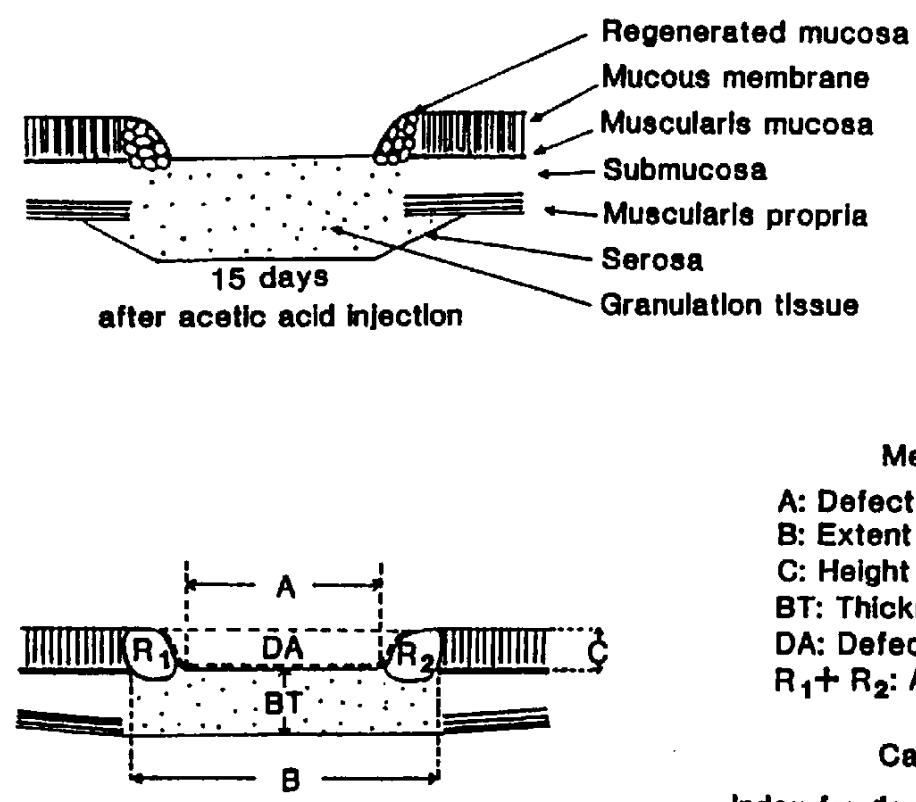

Measurement of ulcerated region

A: Defect of mucosa

B: Extent of ruptured muscularis mucosa

C: Height of marginal mucosa

BT: Thickness of ulcer base

DA: Defective area In ulcerated region

$R_{1}+R_{2}$ : Area of regenerated mucosa

Calculation of Indices

Index for decrease in exposed ulcer floor: $\frac{B-A}{B} \times 100$

Index for mucosal regeneration: $\frac{R_{1}+R_{2}}{C \times B} \times 100$

Fig. 2. Method for histological measurements, showing schematic drawings of the ulcerated region. 
ture. The longitudinal and abscissal lengths of the upper, opened part of the ulcer were measured with a micrometer that was set on a stereoscopic microscope, and the product of both lengths $\left(\mathrm{mm}^{2}\right)$ was expressed in terms of the ulcer index. After the ulcer size was measured, the stomach tissue was again immersed in $10 \%$ formalin for $24 \mathrm{hr}$. The formalin-fixed tissue was then cut so that a little of the normal tissue surrounding the ulcer remained. Thereafter, the central part of ulcer was cut vertically against the serosa along the long diameter. These tissues, cut in half, were embedded in paraffin and cut into 2- to $3-\mu$ m-thick sections. The sections were stained with hematoxylin and eosin. Histological measurements were performed under light micrography of the stained preparations as shown in Fig. 2. The ulcerated regions measured are as follows: A: Defect of mucosa, B: Extent of marginal mucosa, DA: Defective area in the ulcerated region, $R_{1}+R_{2}$ : Area of regenerated mucosa. On the basis of the above measured values, the following indices were calculated: the index for the decrease in exposed ulcer floor $=(B-A) \times 100 / B$ and the index for mucosal regeneration $=\left(R_{1}+R_{2}\right) \times 100 /(C \times B)$. The healing effect of test drugs was evaluated by comparing the ulcer index, the defective area in the ulcerated region, the index for the decrease in the exposed ulcer floor and the index for the mucosal regeneration of each test drug with those of the respective control.

\section{Effects of test drugs on gastric secretion and serum gastrin levels}

The rats were deprived of food but allowed access to water freely for $24 \mathrm{hr}$. After fasting, the zinc-cimetidine complex, cimetidine, $\mathrm{ZnCl}_{2}$ or cimetidine $+\mathrm{ZnCl}_{2}$ was given orally in a volume of $0.5 \mathrm{ml}$. Control animals were given orally the vehicle ( $1 \%$ gum arabic) only instead of test drugs. At $1 \mathrm{hr}$ after the administration of test drug or the vehicle, the pylorus of each rat was ligated under ether anesthesia. At $3 \mathrm{hr}$ after ligation, the gastric contents were collected. The volume of gastric juice was measured, the acidity was determined by an automatic titrator (ABT-101; Tohadenpa, Tokyo) and the total acid output during the 1 -hr period was calculated.

After a 24-hr fast, one of the test drugs described above or the vehicle was given orally. At $1 \mathrm{hr}$ after the administration of test drug or the vehicle, blood samples were collected by decapitation. The serum gastrin levels were determined by using a Gastrin RIA Kit II (Dainabot, Tokyo).

Effects of test drugs on ulcer index and thiobarbituric acid (TBA)-reactive substances in the ulcerated region

Gastric ulcers were induced in the rats with a limited food intake time as mentioned above. The zinc-cimetidine complex, cimetidine, $\mathrm{ZnCl}_{2}$, human $\mathrm{Cu}, \mathrm{Zn}$-SOD or vehicle was given orally, twice daily (10:30 a.m. and 6:30 p.m.) for 9 and 14 consecutive days from the day (the 1 st day) after acetic acid injection. On the 10th and 15th days, the animals were killed by rapid decapitation. The stomachs were removed and then cut open along the greater curvature. After the longitudinal and abscissal lengths of the upper, opened part of the ulcer for the ulcer index were measured, the stomach tissue from the ulcerated region was punched out with a metallic punch $8 \mathrm{~mm}$ in diameter, and the mucosa of the ulcerated region was removed by scraping. TBA-reactive substances in the mucosa were determined by the method of Ohkawa et al. (16). The content of TBA-reactive substances was expressed as nmol of malonedialdehyde per mg protein. TBA (Kanto Chemicals Co., Inc.) and 1,1,3,3-tetramethoxypropane (Tokyo Kasei Co., Tokyo) were used for the TBA assay.

\section{Statistical analyses}

The results obtained are expressed as the means \pm S.E. The data were analyzed by one-way analysis of variance, and the statistical significance among groups was determined by Duncan's multiple-range test.

\section{RESULTS}

\section{Effects on ulcer healing}

The zinc-cimetidine complex given orally, twice daily at doses of $15.0(11.4 \mathrm{mg} / \mathrm{kg}$ as cimetidine), 30.0 and 60.0 $\mathrm{mg} / \mathrm{kg}$ for 14 consecutive days and evaluated on the 15 th day after acetic acid injection decreased the ulcer index by $28 \%, 44 \%$ and $49 \%$, respectively, and the defective area of the ulcerated region by $48 \%, 55 \%$ and $50 \%$, respectivey (Fig. 3). In addition, this compound at oral doses of 30.0 and $60.0 \mathrm{mg} / \mathrm{kg}$ twice daily increased the index for the decrease in the exposed ulcer base by $26 \%$ and $50 \%$, respectively, and the index for mucosal regeneration by $50 \%$ and $76 \%$, respectively.

Cimetidine at oral doses of 45.4 and $90.7 \mathrm{mg} / \mathrm{kg}$ twice daily decreased the ulcer index by $35 \%$ and $48 \%$, respectively, and the defective area of the defective area by $44 \%$ and $47 \%$, respectively (Fig. 4 ). Cimetidine at oral doses of 45.4 and $90.7 \mathrm{mg} / \mathrm{kg}$ twice daily also increased the index for the decrease in the exposed ulcer base by $43 \%$ and $44 \%$, respectively, and the index for mucosal regeneration by $52 \%$ and $65 \%$, respectively.

However, $\mathrm{ZnCl}_{2}$ at oral doses of 12.3 ( $\mathrm{Zn}$ content in 30 $\mathrm{mg} / \mathrm{kg}$ of the zinc-cimetidine complex), 24.5 and 49.0 $\mathrm{mg} / \mathrm{kg}$ twice daily was ineffective on all ulcer parameters (Fig. 5). The ulcer healing effect of the combination of cimetidine and $\mathrm{ZnCl}_{2}$ was similar to that of cimetidine alone (Fig. 6). 

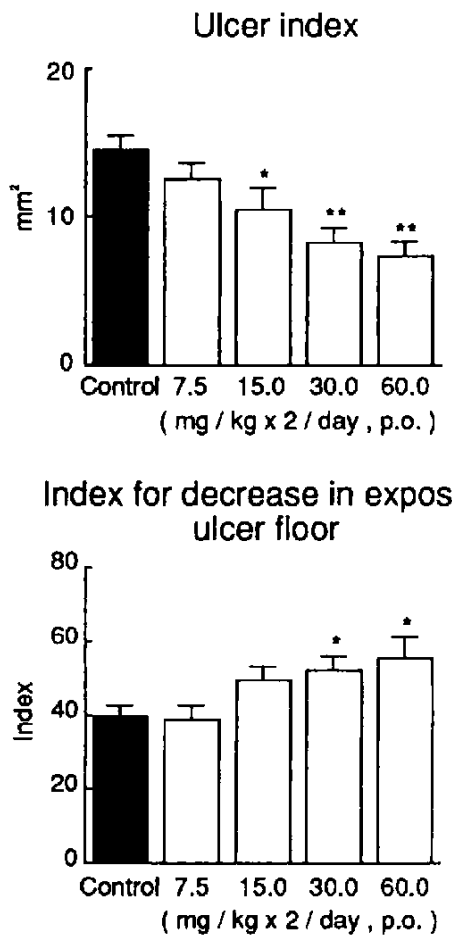

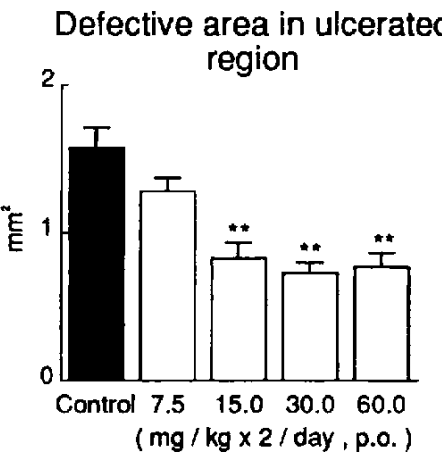

Index for mucosal regeneration

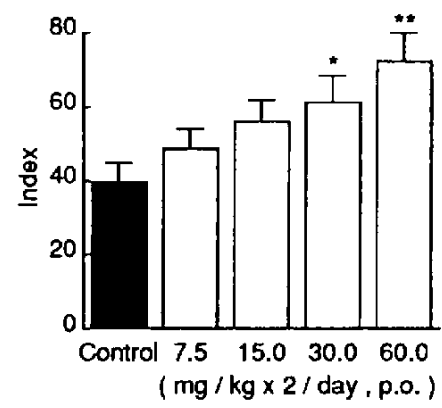

Fig. 3. Effect of the zinc-cimetidine complex on the healing of acetic acid-induced gastric ulcers in rats with a limited food intake time. The zinc-cimetidine complex ( $15.0 \mathrm{mg}$ of this compound contains $11.4 \mathrm{mg}$ of cimetidine) was given orally, twice daily for 14 consecutive days beginning the day after acetic acid injection. Each column denotes the mean \pm S. E. for 8 rats. Significantly different from the respective control, ${ }^{*} \mathrm{P}<0.05,{ }^{*} \mathrm{P}<0.01$.
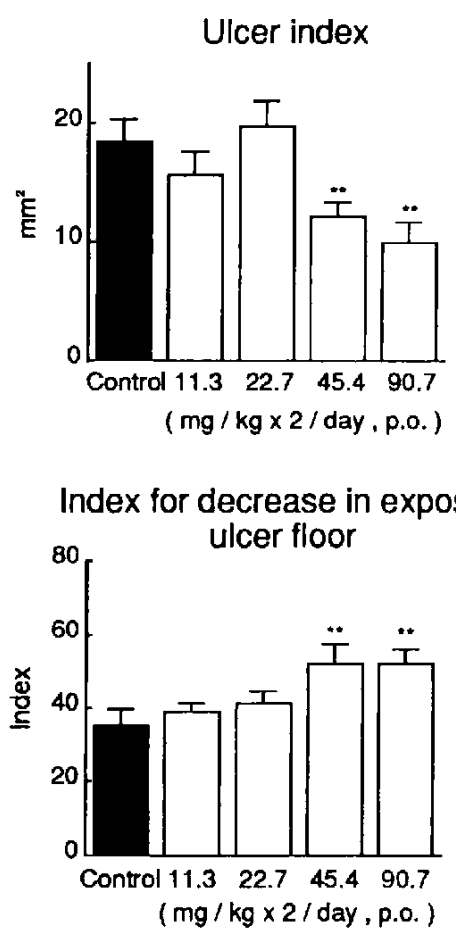
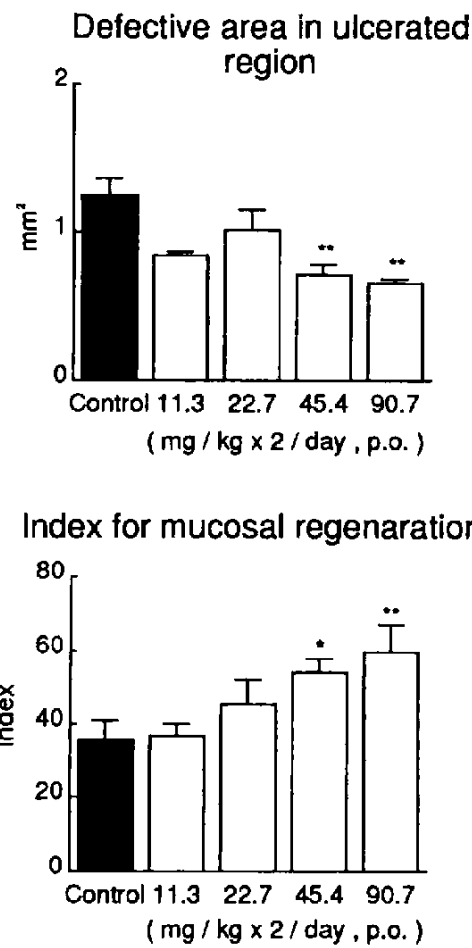

Fig. 4. Effect of cimetidine on the healing of acetic acid-induced gastric ulcers in rats with a limited food intake time. Cimetidine was given orally, twice daily for 14 consecutive days beginning the day after acetic acid injection. Each column denotes the mean \pm S.E. for 9 to 10 rats. Significantly different from the respective control, ${ }^{*} \mathrm{P}<0.05,{ }^{* *} \mathrm{P}<0.01$. 

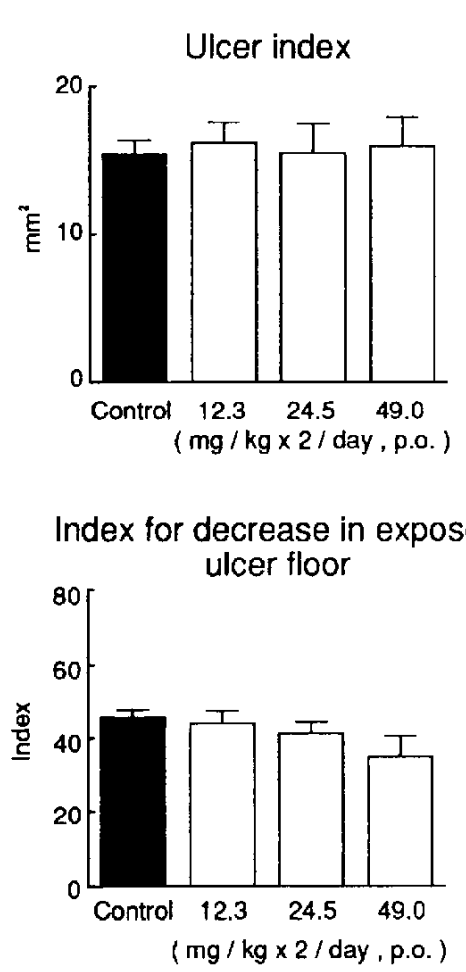

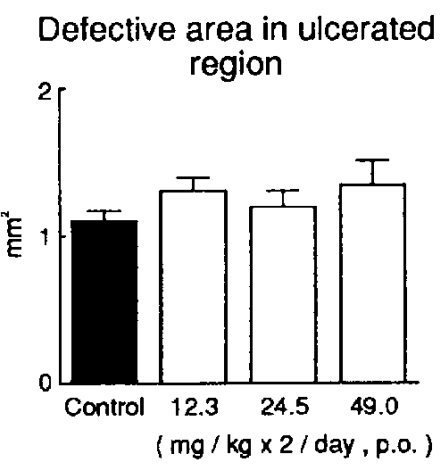

Index for mucosal regeneration

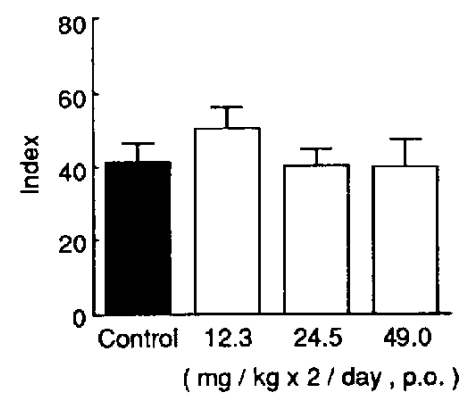

Fig. 5. Effect of $\mathrm{ZnCl}_{2}$ on the healing of acetic acid-induced gastric ulcers in rats with a limited food intake time. $\mathrm{ZnCl}$ (the $\mathrm{Zn}$ content in $12.3 \mathrm{mg}$ of $\mathrm{ZnCl}_{2}$ is equal to that in $30 \mathrm{mg}$ of the zinc-cimetidine complex) was given orally, twice daily for 14 consecutive days beginning the day after acetic acid injection. Each column denotes the mean \pm S.E. for 8 to 10 rats.

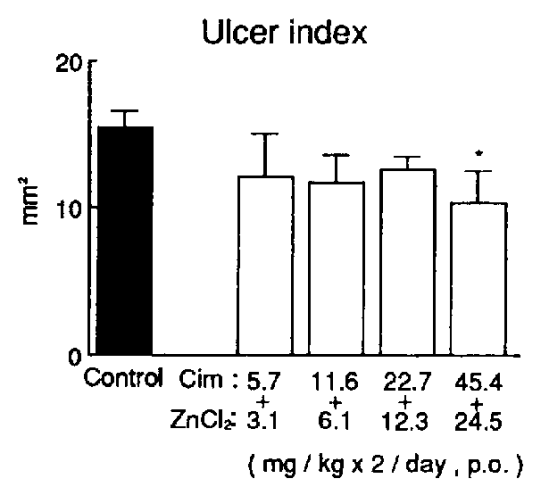

Index for decrease in exposed

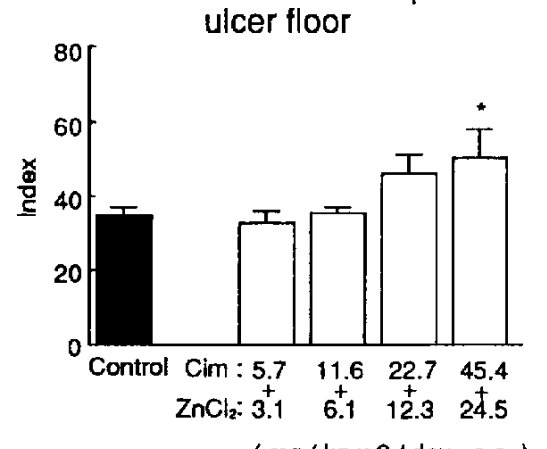

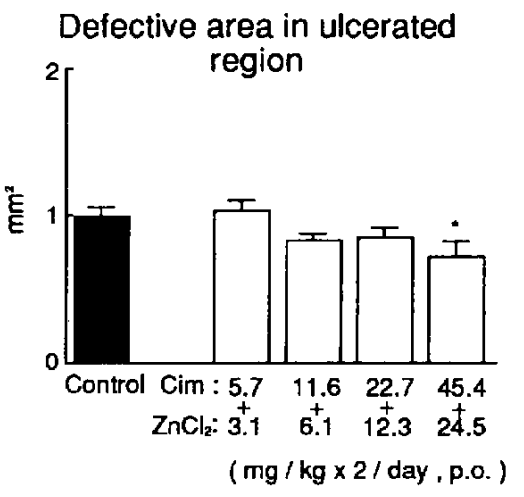

Index for mucosal regeneration

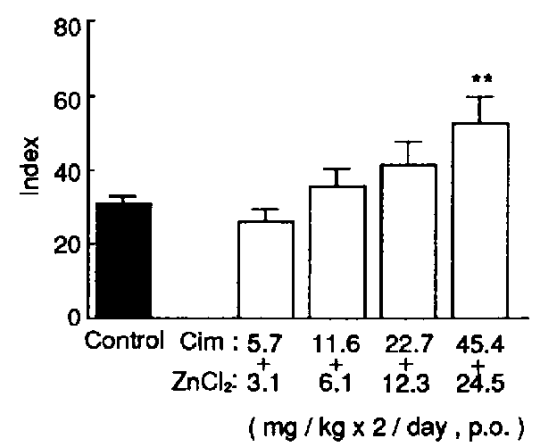

Fig. 6. Effect of the combination of cimetidine ( $\mathrm{Cim})$ and $\mathrm{ZnCl}_{2}$ on the healing of acetic acid-induced gastric ulcers in rats with a limited food intake time. Cim and $\mathrm{ZnCl}_{2}$ were simultaneously given orally, twice daily for 14 consecutive days beginning the day after acetic acid injection. Each column denotes the mean \pm S.E. for 8 to 10 rats. Significantly different from the respective control, ${ }^{*} \mathrm{P}<0.05,{ }^{* *} \mathrm{P}<0.01$. 
Effects on gastric acid secretion and serum gastrin levels

A single oral administration of the zinc-cimetidine complex at $60 \mathrm{mg} / \mathrm{kg}$ to normal rats slightly $(37 \%)$, but significantly, inhibited the basal gastric acid outputs (Fig. 7A). However, oral administration of less than $30 \mathrm{mg} / \mathrm{kg}$ of this compound did not affect acid secretion. Serum gastrin levels were also significantly elevated only by a single oral administration of $60 \mathrm{mg} / \mathrm{kg}$ of the compound to normal rats (a $104 \%$ elevation) (Fig. 7A). Cimetidine at oral doses of 45.4 and $90.7 \mathrm{mg} / \mathrm{kg}$ markedly inhibited the basal gastric acid outputs by $66 \%$ and $91 \%$, respectively (Fig. 7B). In addition, cimetidine at 45.4 and $90.7 \mathrm{mg} / \mathrm{kg}$ markedly elevated the serum gastrin levels by $375 \%$ and $533 \%$, respectively (Fig. 7B). $\mathrm{ZnCl}_{2}$ at an oral dose of 24.5 $\mathrm{mg} / \mathrm{kg}$ ( $\mathrm{Zn}$ content in $60 \mathrm{mg} / \mathrm{kg}$ of the zinc-cimetidine complex) affected neither basal gastric acid outputs nor serum gastrin levels (data not shown). In addition, the effects of the combination of cimetidine $(45.4 \mathrm{mg} / \mathrm{kg}$, p.o.) and $\mathrm{ZnCl}_{2}(24.5 \mathrm{mg} / \mathrm{kg}$, p.o.) on basal acid secretion and serum gastrin levels were similar to that of cimetidine alone (data not shown).
Effects on ulcer index and TBA-reactive substances in the ulcerated regions

The zinc-cimetidine complex ( 30.0 and $60.0 \mathrm{mg} / \mathrm{kg}$ ), cimetidine $(45.4 \mathrm{mg} / \mathrm{kg})$ and $\mathrm{Cu}, \mathrm{Zn}$-human SOD (10 $\mathrm{mg} / \mathrm{kg}$ ) given orally, twice daily for 14 consecutive days and evaluated on the 15 th day significantly decreased the ulcer index, although these drugs given for 9 consecutive days were ineffective on this index (Fig. 8A). On the 10th and 15 th days after acetic acid injection, the TBA-reactive substances in the ulcerated region from control rats were over tenfold higher than those in the unulcerated region (Fig. 8B). The zinc-cimetidine complex (30.0 and $60.0 \mathrm{mg} / \mathrm{kg}$ ), cimetidine $(45.4 \mathrm{mg} / \mathrm{kg}$ ) and $\mathrm{Cu}, \mathrm{Zn}$-human SOD $(10 \mathrm{mg} / \mathrm{kg})$ given orally, twice daily for 9 or 14 consecutive days significantly inhibited the increase in TBAreactive substances in the ulcerated region (Fig. 8B). However, $\mathrm{ZnCl}_{2}$ at the oral dose of $24.5 \mathrm{mg} / \mathrm{kg}$ twice daily for 9 or 14 consecutive days was ineffective on both the ulcer index and TBA-reactive substances (data not shown).
A

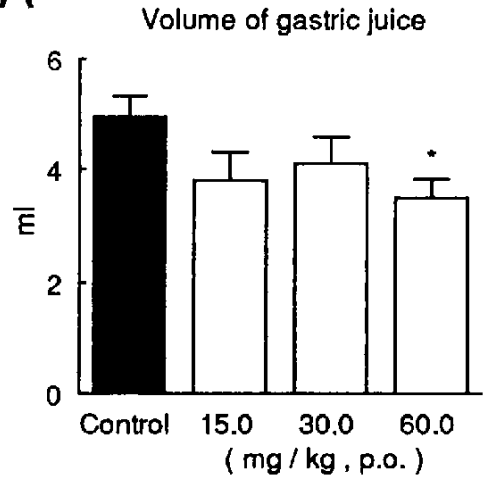

B

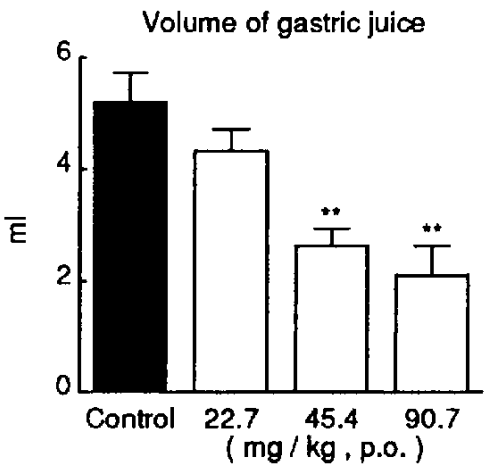

Total acid output
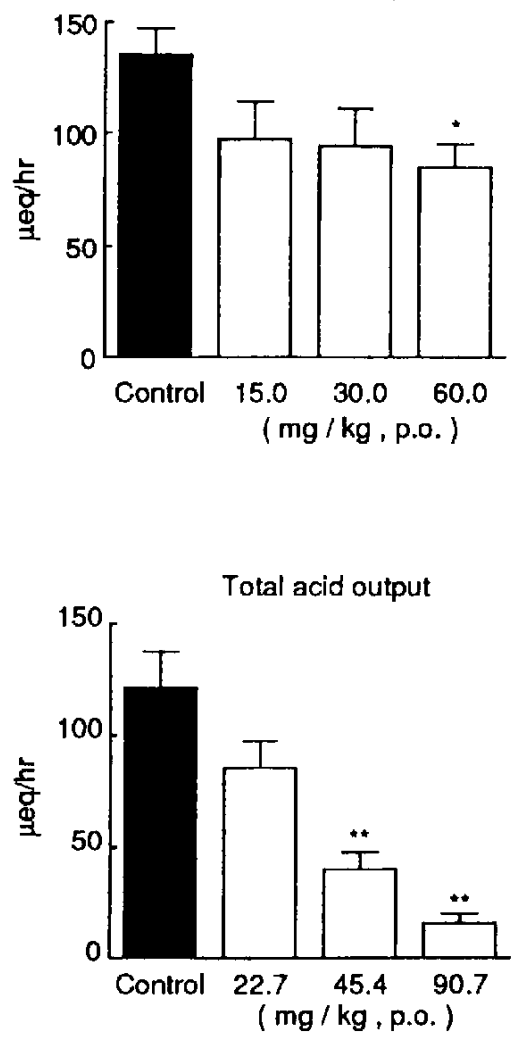

Serum gastrin
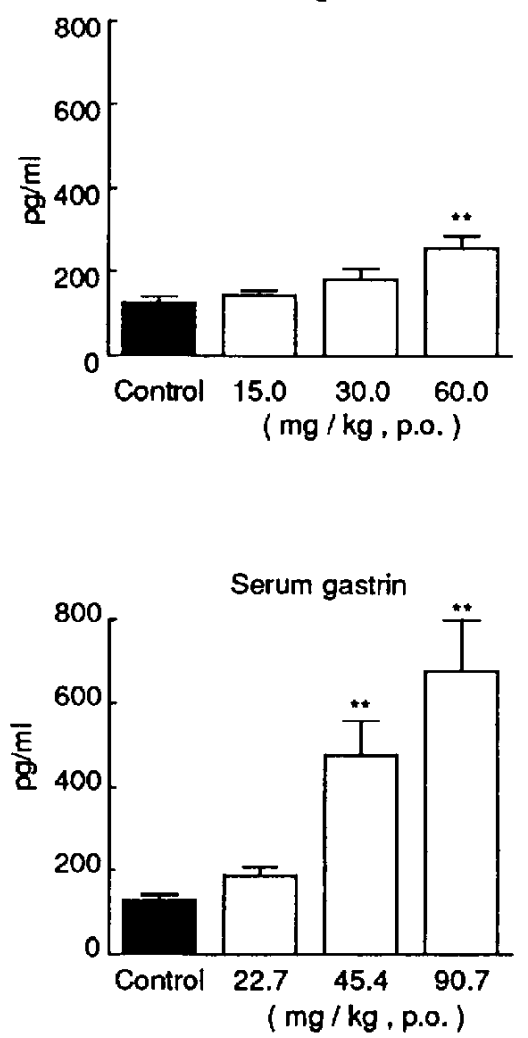

Fig. 7. Effect of the zinc-cimetidine complex (A) and cimetidine (B) on gastric acid secretion and serum gastrin levels in normal rats. To measure gastric acid secretion, the pylorus of each rat was ligated for $3 \mathrm{hr}$ from $1 \mathrm{hr}$ after oral administration of test drugs. To measure serum gastrin levels, blood samples were collected by decapitation at $1 \mathrm{hr}$ after the administration of the drug. Each column denotes the mean \pm S.E. for 8 rats. Significantly different from the respective control, ${ }^{*} \mathrm{P}<0.05,{ }^{* *} \mathrm{P}<0.01$. 
A
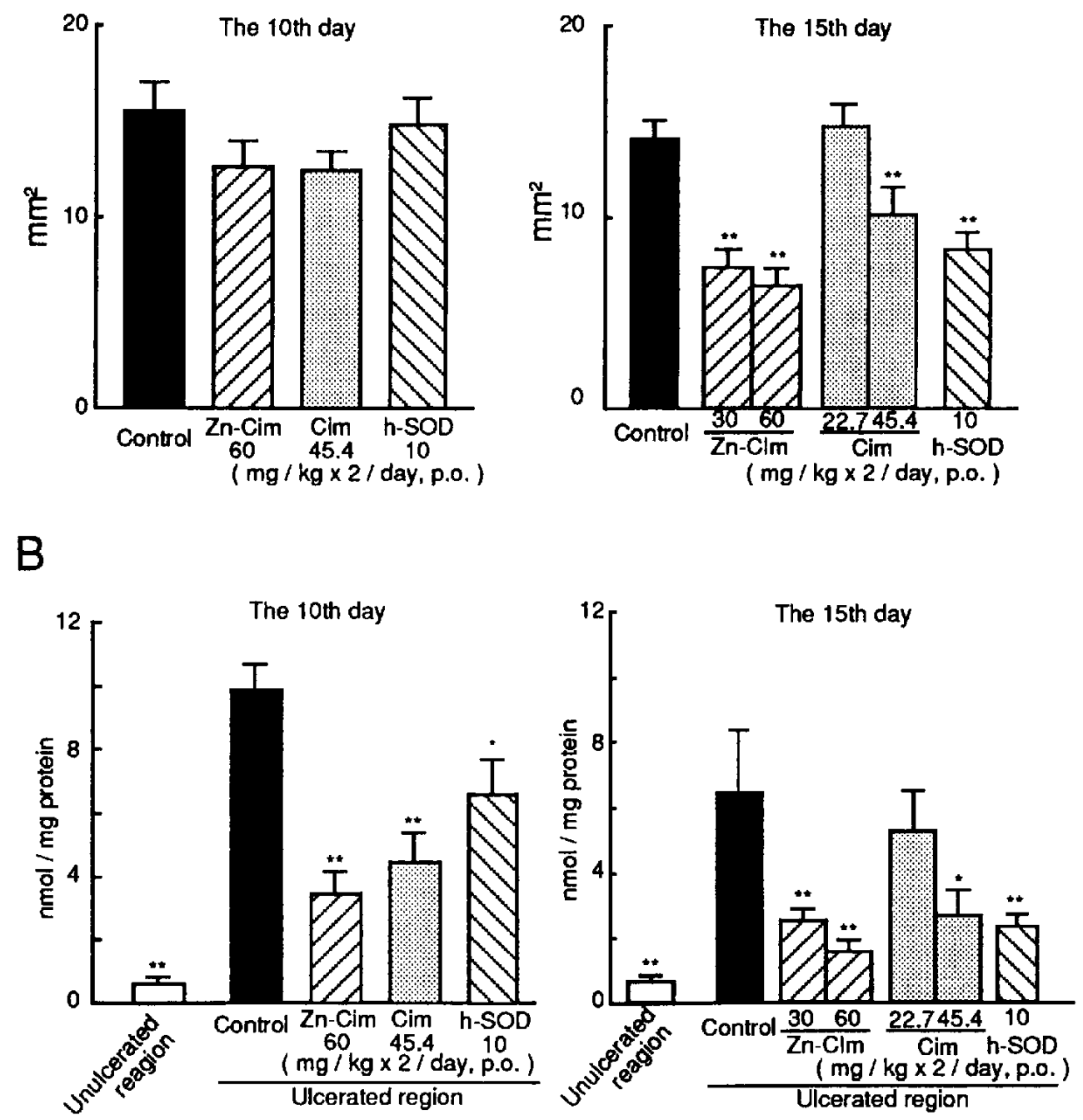

Fig. 8. Effects of the zinc-cimetidine complex (Zn-Cim), cimetidine (Cim) and human Cu, Zn-SOD (h-SOD) on ulcer index (A) and thiobarbituric acid (TBA)-reactive substances (B) in the ulcerated region. $\mathrm{Zn}$-Cim, Cim or h-SOD was given orally, twice daily for 14 consecutive days beginning the day after the acetic acid injection. Each column denotes the mean \pm S.E. for 7 to 10 rats. Significantly different from the respective control, ${ }^{*} \mathrm{P}<0.05,{ }^{* *} \mathrm{P}<0.01$.

\section{DISCUSSION}

The present study indicates that the zinc-cimetidine complex is a new compound having quite different properties from zinc and cimetidine, the components, and it exhibits a more potent healing effect than that of cimetidine on chronic gastric ulcers in rats with a limited food intake time. This study also suggests that the inhibition of lipid peroxidation in the ulcerated region by this compound could be attributed to its ulcer-healing action.

Acetic acid-induced gastric ulcers in rats have been widely used to evaluate the ulcer healing effects of antiulcer agents, because histopathological changes in the healing of this ulcer model closely resemble those in human chronic gastric ulcers (15). Recently, we have demonstrated that cimetidine, a histamine $\mathrm{H}_{2}$-receptor antagonist, and omeprazole, a proton pump inhibitor, are more effective in accelerating the healing of acetic acid-induced gastric ulcers in rats with a limited food intake time in comparison to rats with an unlimited food intake time (9). Therefore, in the present study, we used acetic acid-induced gastric ulcers in rats with a limited food intake time to evaluate the effect of the zinc-cimetidine complex on the healing of gastric ulcers.

In the present study, the zinc-cimetidine complex at oral doses of more than $15.0 \mathrm{mg} / \mathrm{kg}$ twice daily significantly promoted the ulcer healing. On the other hand, cimetidine was significantly effective at oral doses of more than 
$45.4 \mathrm{mg} / \mathrm{kg}$, twice daily. These results indicate that the zinc-cimetidine complex at $1 / 4$ the dose of cimetidine is as effective as cimetidine when the ulcer-healing effects of both compounds were compared as the same dose of cimetidine, because $15 \mathrm{mg}$ of the zinc-cimetidine complex contains $11.4 \mathrm{mg}$ of cimetidine. However, $\mathrm{ZnCl}_{2}$ was ineffective even at an oral dose of $49.0 \mathrm{mg} / \mathrm{kg}$, twice daily (the $\mathrm{Zn}$ content in $49.0 \mathrm{mg}$ of $\mathrm{ZnCl}_{2}$ is equal to that in $120.0 \mathrm{mg}$ of the zinc-cimetidine complex). Frommer (17) reported that zinc sulfate given by mouth $(220 \mathrm{mg}$, three times a day) accelerated the healing of gastric ulcers in humans. This discrepancy between our result and his may be due to the differences in humans and rats or doses of zinc. In addition, the effect of the combination of cimetidine and $\mathrm{ZnCl}_{2}$ was equal to that of cimetidine alone. These results suggest that the antiulcer effect of the zinc-cimetidine complex may be due to the action of a new chelate compound that consists of cimetidine and zinc rather than to the synergismic action of cimetidine and zinc.

It is generally believed that histamine $\mathrm{H}_{2}$-receptor antagonists and proton pump inhibitors accelerate the healing of gastric ulcers by potent and long-lasting antisecretory actions. The other main action of both types of agents is to cause hypergastrinemia. Gastrin has been indicated to possess trophic actions such as inducing the proliferation of gastric mucosal cells $(18-20)$ in addition to stimulation of gastric acid secretion. We have already reported that cimetidine and omeprazole mainly accelerate the healing of gastric ulcers by the trophic action of gastrin via the increase in gastrin secretion (21). Therefore, in the next experiment, we investigated the effects of the zinccimetidine complex on gastric acid secretion and serum gastrin levels to clarify the mechanism of the ulcer-healing promoting action of this compound. In the present study, a single oral administration of the zinc-cimetidine complex at $60 \mathrm{mg} / \mathrm{kg}$ to normal rats was slightly but significantly effective in inhibiting gastric acid secretion and in elevating serum gastrin levels. However, this compound at doses of 15 and $30 \mathrm{mg} / \mathrm{kg}$, which had been proved to accelerate the ulcer healing, did not affect either parameter. In contrast, cimetidine ( 45.4 and $90.7 \mathrm{mg} / \mathrm{kg}$, p.o.) markedly inhibited acid secretion and elevated serum gastrin levels. Accordingly, it is unlikely that the ulcer healing-promoting action of the zinc-cimetidine complex is related to the inhibition of acid secretion or to the elevation of gastrin secretion. In addition, this finding also indicates that the zinc-cimetidine complex is a new compound that has lost the properties of histamine $\mathrm{H}_{2}$ receptor antagonists. It has been recognized that the absorption of the zinc-cimetidine complex given orally to rats from the gastrointestinal tract is very low, while its excretion into feces is very high (unpublished data, Minobe et al.). It is postulated from these findings that the antiulcer action of the zinc-cimetidine complex in contrast with cimetidine may be due to its local action.

Recently we demonstrated that neutrophils and TBAreactive substances were markedly increased in the ulcerated region after acetic acid-induced gastric ulcers in rats with a limited food intake time and then decreased gradually as the day went on (10). This result strongly suggests that neutrophils-generated free radicals are important factors for the delay of the healing of this ulcer model. In the present experiment, human $\mathrm{Cu}, \mathrm{Zn}-\mathrm{SOD}(10 \mathrm{mg} / \mathrm{kg}$ $\times 2$ /day, p.o.) as well as the zinc-cimetidine complex and cimetidine exhibited a marked ulcer-healing promoting action. These three kinds of drugs had already inhibited the increase in TBA-reactive substances (lipid peroxidation) in the ulcerated region before the ulcer-healing effects of these drugs were recognized. These findings suggest that the ulcer-healing promoting action of the zinc-cimetidine complex may be due to the inhibition of lipid peroxidation in the ulcerated region but not due to the inhibition of acid secretion or the trophic effect of gastrin. However, the mechanism by which this compound inhibits lipid peroxidation remains unclear. Further study is needed to clarify the mechanism. Cimetidine was also effective in inhibiting lipid peroxidation. Cimetidine has been shown to be a powerful hydroxyl radical scavenger (22). Therefore, the hydroxyl radical-scavenging property of cimetidine may be partly related to its ulcer-healing effect.

Recently, it was indicated that Helicobacter $(H)$ pylori infection may be associated with the pathogenesis of peptic ulcers $(23-25)$ or relapse of peptic ulcers because the relapse rate is markedly reduced after successful eradication $(26,27)$. The mechanism by which $H$. pylori causes mucosal damages remains unclear. It has been suggested that free radicals formed by neutrophils infiltrated in the mucosa may be involved in the mucosal damages or ulcer relapse elicited by $H$. pyroli (28). Therefore, the free radical-scavenging action of the zinc-cimetidine complex may be also effective in preventing the mucosal damages or ulcer relapse elicited by $H$. Pyrori.

\section{Acknowledgments}

The authors wish to thank A. Ito, A. Suzuki, M. Ishihara and K. Nakamori for their technical assistance.

\section{REFERENCES}

1 Pories WJ, Henzel JH, Rob CG and Strain WH: Acceleration of wound healing in man with zinc sulfate given by mouth. Lancet 1, 121-126 (1967)

2 Greaves MW and Skillen AM: Effects of long-continued ingestion of zinc sulfate in patients with venous leg ulceration. Lancet 2, 889-896 (1970)

3 Ogle $\mathrm{CW}$ and $\mathrm{Cho} \mathrm{CH}$ : Observation on the influence of graded pretreatment doses of zinc sulfate on the gastric effects of reser- 
pine in rats. Pharmacol Res Commun 10, 325-335 (1978)

4 Cho $\mathrm{CH}$ and Ogle $\mathrm{CW}$ : A correlative study of the antiulcer effects of zinc sulfate in stressed rats. Eur J Pharmacol 48, 97-105 (1978)

5 Cho CH, Hua MF, Chou CK and Ho LT: Protection of zinc sulfate against gastric necrosis induced by ethanol in rats. Proc Natl Sci Counc Repub China B 7, 261-267 (1983)

6 Cho $\mathrm{CH}$ and Ogle $\mathrm{CW}$ : The effect of zinc sulfate on vagalinduced mast cell changes and ulcers in the rat stomach. Eur $\mathbf{J}$ Pharmacol 43, 315-322 (1977)

7 Kazimicrczak W and Maslinski C: The effect of zinc ions on selective and nonselective histamine release in vitro. Agents Actions 4, 1-6 (1974)

8 Cho $\mathrm{CH}, \mathrm{Pfeiffer} \mathrm{CJ}$ and Cheema, A: Studies of zinc and histamine on lysosomal fragility: Possible role in stress ulceration. Pharmacol Biochem Behav 13, 41-44 (1980)

9 Ito M, Segami T, Tsukahara T, Kojima R and Suzuki Y: Effect of cimetidine and omeprazole on gastric ulcer healing of rats with limited food intake time. Eur J Pharmacol 263, 245-251 (1994)

10 Shii $\mathrm{D}$, Inaguma $\mathrm{K}$, Ito $\mathrm{M}$ and Suzuki $\mathrm{Y}$ : Role of oxygen radicals in the healing process of acetic acid-induced ulcers in rats with limited food-intake-time and effects of oxygen radical scavengers on the ulcer healings. Exp Ulcer 19, 105- 109 (1992) (Abstr in English)

11 Yoshikawa T, Naito Y, Tanigawa T, Yoneta T, Oyamada H and Ueda S: Effect of zinc-carnosine chelate compound (Z-103) on burn-induced gastric mucosal injury in rats. $\mathrm{J}$ Clin Biochem Nutr 7, 107-113 (1989)

12 Yoshikawa T, Naito $\mathrm{Y}$, Tanigawa $\mathrm{T}$, Yoneta $\mathrm{T}$ and Kondo $\mathrm{M}$ : The antioxidant properties of a rovel zinc-carnosine chelate compound, $N$-(3-aminopropionyl)-L-histidinato zinc. Biochim Biophys Acta 1115, 15-21 (1991)

13 Ito $M$, Shii D, Segami T, Kojima R and Suzuki Y: Preventive actions of $N$-(3-aminopropyonyl)-L-histidinato zinc (Z-103) through increases in the activities of oxygen-derived free radical scavenging enzymes in the gastric mucosa on ethanol-induced gastric mucosal damage in rats. Jpn J Pharmacol 59, 267-274 (1992)

14 Ito $M$, Tanaka $\mathrm{T}$ and Suzuki Y: Effect of $N$-(3-aminopropionyl)-L-histidinato zinc ( $Z$-103) on healing and hydrocortisoneinduced relapse of acetic acid ulcers in rats with limited foodintake-time. Jpn J Pharmacol 52, 513-521 (1990)
15 Takagi K, Okabe S and Saziki R: A new method for the production of chronic gastric ulcer in rats and the effect of several drugs on its healing. Jpn J Pharmacol 19, 418-426 (1969)

16 Ohkawa $\mathrm{H}$, Onishi $\mathrm{N}$ and Yagi K: Assay for lipid peroxide in animal tissue by thiobarbituric acid reaction. Anal Biochem 95 , $351-358$ (1979)

17 Frommer DJ: The healing of gastric ulcers by zinc sulfate. Med J Aust 22, 793-796 (1975)

18 Willems G, Vansteenkiste $Y$ and Limbosch JM: Stimulating effect of gastrin cell proliferation kinetics in canine fundic mucosa. Gastroenterology 62, 583-589 (1972)

19 Johnson LR and Guthrie PD: Mucosal DNA synthesis: A short term index of the trophic action of gastrin. Gastroenterology 67, 453-459 (1974)

20 Hansen OH, Pedersen T, Laesen JK and Rehfeld JF: Effect of gastrin on gastric mucosal cell proliferation in man. Gut 17 , 536-541 (1976)

21 Ito $M$, Segami $T$, Inaguma $K$ and Suzuki $Y$ : Cimetidine and omeprazole accelerate gastric ulcer healing by an increase in gastrin secretion. Eur J Pharmacol 263, 253-259 (1994)

22 Uchida $\mathrm{K}$ and Kawakishi S: Cimetidine anti-ulcer drug as a powerful hydroxyl radical scavenger. Agric Biol Chem 54, 2485-2487 (1990)

23 Graham DY: Helicobacter pyroli: its epidemiology and its role in duodenal ulcer disease. J Gastroenterol Hepatol 6, 105-113 (1991)

24 Marshall BJ, McGechie DB, Rogers PA and Glancy RJ: Pyloric Campylobacter infection and gastroduodenal disease. Med $\mathbf{J}$ Aust 142, 439-444 (1985)

25 O'Connor HJ: The role of Helicobacter pylori in peptic ulcer disease. Scand J Gastroenterol 29, Supp 201, 11 - 15 (1994)

26 Rauws EAJ and Tytgat GNJ: Cure of duodenal ulcer associated with eradication of Helicobacter pylori. Lancet 335, 1233-1235 (1990)

27 Graham DY, Lew GM, Klein PPD, Evans DG, Evans DJ, Saeed ZA and Malaty HM: Effect of treatment of Helicobacter pylori infection on the long-term recurrence of gastric or duodenal ulcer: A randomized, controlled study. Ann Intern Med 116, 705-708 (1992)

28 Wallace JL: Possible mechanisms and mediators of gastritis associated with Helicobacter pylori infection. Scand J Gastroenterol 26, Supp 187, 65-70 (1991) 